\title{
Spectrophotometric Determination of Apixaban in Bulk Drug and Oral Dosage Formulation
}

\author{
Deepshikha Sharma ${ }^{1}$, Vikramsinh R. Chauhan ${ }^{1}$, Kartik B. Vyas \\ ${ }^{1}$ Department of Chemistry, Sheth L.H. Science College, (Scholars of Gujarat University, Ahmedabad) \\ Mansa, India \\ ${ }^{2 *}$ Department of Chemistry, Sheth L.H. Science College, Mansa, Gujarat University, Ahmedabad, India.
}

\begin{abstract}
A simple, rapid, cost effective and extractive UV-Vis spectrophotometric method has been developed for the determination of Apixaban (AP) in bulk drug and pharmaceutical formulation. It was based on UV-Vis spectrophotometric measurements in which the drug reacts chromogenic reagent ( $\mathrm{N}$-(1-napthyl) ethylene diamine dihydrochloride solution) in acidic medium and give stable pale yellow colored complex which exhibits absorption maximum at $680 \mathrm{~nm}$. Beer's law was obeyed in the concentration range of $5-50 \mu \mathrm{g} / \mathrm{ml}$. This method was tested and validated for various parameters according to ICH guidelines. The proposed method was successfully applied for the determination of AP in oral formulation. The results demonstrated that the procedure is accurate, precise and reproducible (relative standard deviation $<2 \%$ ). As it is simple, cheap and less time consuming, it can be suitably applied for the estimation of LA in dosage forms in quality control labs.
\end{abstract}

Keywords : Apixaban, Spectrophotometric, UV-Vis, Atrial fibrillation, DOAC

\section{INTRODUCTION}

Atrial fibrillation (AF) is an uneven heart rhythm. It is measured the most frequent cardiac arrhythmia and increases the risk of strokes [1]. In order to avoid strokes, anticoagulants are routinely prescribed, particularly along with the CHA2DS2- VASc score greater than or equal to double [2]. CHA2DS2-VASc and CHADS2 risk models are preferred tools to estimate the risk of embolic strokes in patients with atrial fibrillation $[3,4]$. Warfarin reduces the risk of strokes by $68 \%$ and however requires regular international normalized ratio testing and has frequent interactions with multiple drugs and food. In recent years, researchers have overcome these limitations by introducing a new class of anticoagulants called nonvitamin $\mathrm{K}$ oral anticoagulants (NOACs) or as "direct oral anticoagulants" (DOACs). Clinical trials have demonstrated that NOACs are equivalent to warfarin in effectiveness and safety and therefore are now routinely used in practice [5-8].

DOACs have the advantage of a quick response time than warfarin. However, they also have relatively short elimination half-lives. $[9,10]$ This is a challenge because nonadherence can be expected to be even more common for DOACs than for warfarin since the patients are not regularly monitored. Exclusion of only a few doses will increase the risk of thromboembolic events. Moreover, although DOACs have a lower pharmacokinetic and pharmacodynamic variability than warfarin and also fewer drug-drug interactions, reduced hepatic metabolism and 
impaired renal function may cause supratherapeutic drug concentrations with an increased risk of bleeding.[11] Subsequently, even when using recommended doses, a certain number of those treated with DOACs will either have high plasma concentrations with an increased risk of bleeding or low plasma concentrations with an increased risk of developing a thromboembolic episode.[12] As there seems to be a direct association between the plasma concentration of the DOAC and the anticoagulation effect,[13] the existence of therapeutic plasma concentration ranges where the risk of these endpoints is lower can be predicted.

Apixaban is a pyrazole derivative small-molecule, act as a potent, oral, and reversible agent. [14]. It represents a new oral anticoagulant molecule, and it received approval in European in 2011, being approved in prevention of stroke and systemic embolism in adults with non-valvular atrial fibrillation, for treatment of deep venous thrombosis, pulmonary embolism and for the prevention of recurrence of DVT and PE after elective hip or knee replacement surgery [15]. The available proof provided by the pre- approval studies and various analysis of emerging clinical experience suggest that apixaban is non-inferior to existing standard antithrombotic therapies and that it has improved safety, expressed as reduced hemorrhagic risk [16-18].

At therapeutic doses, the absolute bioavailability of apixaban is approximately $50 \%$, with low to moderate within subject and inter-subject exposure variability and with linear pharmacokinetics.

Cmax is reached approximately $3 \mathrm{~h}$ post dose in healthy volunteers. Apixaban's plasma protein binding is approximately $87 \%$ and it has a half-life of approximately 12 hours. It has multiple routes of elimination, with $27 \%$ of the total clearance being attributed to the renal excretion. The main metabolic pathway is through CYP3A4/5, P-glycoprotein and breast cancer resistance protein (BCRP) being involved in its transport. Because Apixaban is metabolized by the liver (partially by CYP 3A4) there are few recommendations to prescribe it to patients with hepatic impairment. No dosage adjustment of Apixaban is necessary in patient with mild hepatic impairment, but it should be used with cautions in patients with moderate liver disease (Child class Pugh A or B) and a discontinuation period up to 5 days can be considered before elective surgery in such patients [19]. The present clinical experience allows its administration in renal impairment with a creatinine clearance $\geq 15 \mathrm{ml} / \mathrm{min}$. This is best done by calculating creatinine clearance using CockcroftGault formula (some calculators are also available online), but with some adjustments regarding bodymass index [19]. Strong inhibitors or inducers of both CYP3A4 and P-glycoprotein can markedly influence the plasmatic concentrations of apixaban if coadministered. There are no interactions between food and pharmacokinetics and pharmacodynamics of apixaban [20]. Apixaban has high oral bioavailability and it is absorbed throughout the gastrointestinal tract. Despite this feature, currently there are no warnings or recommendations regarding its use in special populations at high risk for developing venous thromboembolism (after gastric bypass surgery, lapband weight loss surgery or extended resection of the small bowel) [20].

Liquid chromatography coupled with tandem mass spectrometry (LC-MS/MS) is the reference method used in therapeutic monitoring of novel direct oral anticoagulants due its precision, accuracy, sensitivity and robustness [21-24]. There are several pharmacokinetics studies of apixaban [25-26] and assessments of different laboratory tests [27] that used LC-MS/MS for quantification of apixaban in human 
plasma. The main objective of our study was to develop and validate a specific and quantitative high throughput LC-MS/MS method for the analysis of apixaban in human plasma with applicability in clinical therapeutic drug monitoring, pharmacokinetics, as well as in bioequivalence studies. The protocol study was reviewed and validated by the Ethics Committee of the University of Medicine and Pharmacy of Tirgu Mures and has been performed in the accordance with standards of the Declaration of Helsinki and local regulations. All subjects provided written informed consent.

\section{METHODS AND MATERIAL}

All employed chemicals were of analytical grade and highly purified water was used. Apixaban (AP) was provided as a gift sample by Lupin pharmaceuticals Ltd. Aurangabad, India., Sodium nitrite, Ammonium sulfamate, B.M reagent (N-(1-napthyl) ethylenediamine dihydrochloride solution) (Merck, Mumbai, India), hydrochloric acid ( $\mathrm{HCl}$ ) ((Sd fine Chem Ltd., Mumbai, India)

\section{Solution Preparations}

Sodium nitrite solution $(0.1 \% \mathrm{w} / \mathrm{v})$ : $100 \mathrm{mg}$ of sodium nitrite was dissolved in distilled water and made up to $100 \mathrm{ml}$.

Hydrochloric acid (5N): $425 \mathrm{ml}$ of concentrated HCL was taken and diluted to $1000 \mathrm{ml}$ with distilled water.

Ammonium Sulfamate Solution (0.1\%W/V): $500 \mathrm{mg}$ of ammonium sulfamate was dissolved in distilled water and made up to $100 \mathrm{ml}$ with distilled water.

B.M Reagent (N-(1-napthyl) ethylene diamine dihydrochloride solution) (0.1\%w/v): $100 \mathrm{mg}$ of B.M reagent was dissolved in $100 \mathrm{ml}$ of distilled water.
Preparation of the standard drug solution $(1 \mathrm{mg} / \mathrm{ml})$ : $100 \mathrm{mg}$ Apixaban (AP) accurately weighed and transferred into $100 \mathrm{ml}$ volumetric flask, dissolved and diluted to $100 \mathrm{ml}$ with methanol.

Preparation of working standard solution $(100 \mu \mathrm{g} / \mathrm{ml})$ : Accurately $10 \mathrm{ml}$ of standard stock solution was transferred in to $100 \mathrm{ml}$ volumetric flask and then diluted up to mark by water.

\section{Analytical Procedure}

In $100 \mathrm{ml}$ volumetric flask, required volume of AP working standard solution has transferred. To each flask $1 \mathrm{ml}$ of $5 \mathrm{~N} \mathrm{HCl}$ and $1 \mathrm{ml}$ of $0.1 \% \mathrm{w} / \mathrm{v}$ sodium nitrite were added and shaken for 10 minutes. To this, $1 \mathrm{ml}$ of $0.5 \% \mathrm{w} / \mathrm{v}$ ammonium sulfamate was added followed by the addition of $1 \mathrm{ml}$ of B.M reagent. The absorbance was measured at $680 \mathrm{~nm}$ against the reagent blank.

\section{Validation of Method}

Analytical method validation is the systematic steps to confirm that the developed analytical procedure is applicable for a specific analysis. Analytical data of this validation process can be used to evaluate the quality and consistency of developed method.

\section{System suitability}

System suitability parameter is not mandatory for UV-Vis spectroscopic systems. However, to develop more dependable analysis method this parameter is important to perform. A $100 \%$ concentrate of standard solution of had taken and the absorbance of this is measured at the wavelength of maximum absorbance. The E $1 \% 1 \mathrm{~cm}$ values were also calculated and were found to be within specified percentage.

\section{Linear dynamic Range}

The linearity of the suggested methods was determined by calibration curve of apixaban in the range of $0.5-50 \mu \mathrm{g} / \mathrm{ml}$. The calibration curve was made by plotting concentration versus absorbance and carried out linear regression analysis. 


\section{Limit of detection (LOD)}

The lowest concentration of analyte in sample which can be detected by cannot be quantified under the same experimental condition. Limit of detection was calculated from calibration curve using following equation.

$\mathrm{LOD}=3.3 \sigma / \mathrm{S}$

Where $\sigma=$ S.D of y-intercept of calibration curves $\mathrm{S}=$ Mean of slope of calibration curve

\section{Limit of quantification (LOQ)}

The lowest concentration of analyte from sample which can precisely and accurately measured under same experimental condition. Limit of quantification was calculated from calibration curve using following equation.

$\mathrm{LOQ}=10 \sigma / \mathrm{S}$

Where $\sigma=$ S.D of y-intercept of calibration curves

$\mathrm{S}=$ Mean of slope of calibration curve

\section{Precision}

Precision was determined by calculating intra- day and inter-day variations of the developed method in 3 replicates at their different concentrations of AP (10, 20 and $30 \mu \mathrm{g} / \mathrm{ml})$. The absorbances of the solutions were measured at $680 \mathrm{~nm}$. For intra-day precision, analyzed these solutions in triplicates on same day. To determine inter-day precision each of three samples was analyzed on different day.

\section{Accuracy}

Recovery study has performed to evaluate the accuracy of proposed method. In this method, standard drug was added at three different levels i.e. $50 \%, 100 \%$ and $150 \%$ to known pre - analyzed sample solution. By using the proposed method the total concentrations were determined.

\section{Sensitivity parameters}

The molar absorptivity and Sandell's Sensitivity has calculated as per their standard formula as given below. Molar absorptivity is a characteristic constant of the species under consideration. It is the absorbance at the specified wavelength of solution of a compound of unit molar concentration measured in $10 \mathrm{~mm}$ path length.

Molar absorptivity can be evaluated from the following equation.

\section{Molar absorptivity $=$ Slope $\mathrm{x}$ molecular weight $\mathrm{x} 103$ lit/ mol.cm}

Sandell's index represents the number of micrograms or nanograms of the determinant per millilitre of a solution having an absorbance of 0.001 for the cell path length of $1 \mathrm{~cm}$ and is a suitable parameter for expressing and comparing the sensitivities of developed UV-VIS-spectrophotometric methods [15, 30].

\section{Sandell's sensitivity $=$ Molecular weight $/$ Molar absorptivity}

\section{Application of proposed method for formulation}

Procedure for assay of drugs in dosage forms:

Twenty tablets of commercial samples of Apixaban are accurately weighed and powdered. A quantity of powder equivalent to $25 \mathrm{mg}$ of drug is taken and transferred to a $50 \mathrm{ml}$ volumetric flask. The sample is first dissolved in methanol $(25 \mathrm{ml})$ and sonicated for about $10-15 \mathrm{~min}$, finally up the volume is made up to the mark with water. The solution is filtered and $10 \mathrm{ml}$ from above stock solution is transferred to a $100 \mathrm{ml}$ volumetric flask and the volume is adjusted to $100 \mathrm{ml}$ with methanol to give final strength $(50 \mu \mathrm{g} / \mathrm{ml})$.

\section{RESULTS AND DISCUSSION}

In this method in the presence of acidic environment sodium nitrite can diazatitation of drug molecule and this diazonium salt of drug molecule coupled with B.M. regent which can be indicated by dark blue colour 


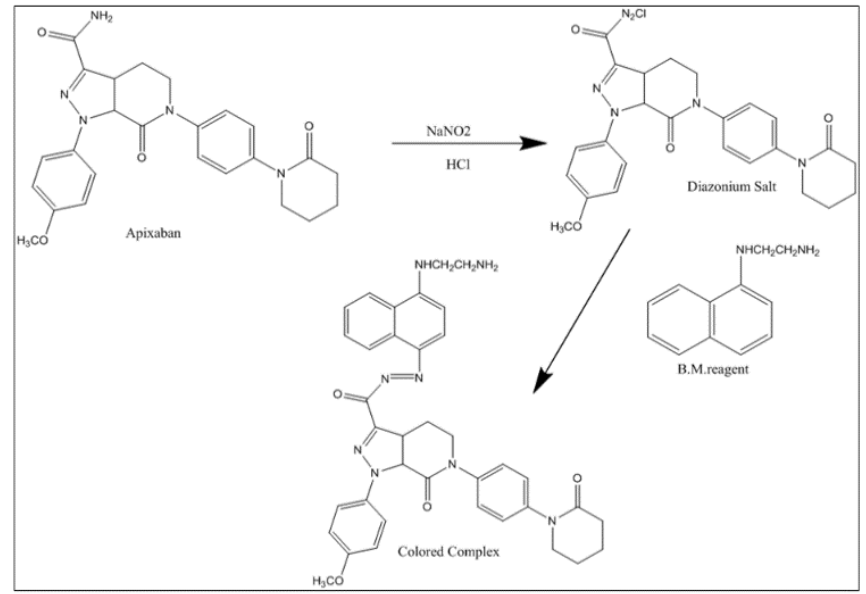

Figure 1 : Mechanism of Colour complex formation

\section{System suitability experiment}

Solutions of standard AP having a concentration of $20 \mu \mathrm{g} / \mathrm{ml}$ and $10 \mu \mathrm{g} / \mathrm{ml}$ were taken. The abso rbance value of these solutions was recorded five times and the $\mathrm{E} 1 \% 1 \mathrm{~cm}$ values were calculated as per the equation below.

\section{$\mathrm{E} 1 \% 1 \mathrm{~cm}=$ Absorbance value $/$ Concentration $(\mathrm{g} / 100$ $\mathrm{ml}$ )}

The results of the system suitability experiments are tabulated in Table 1 . The \% RSD of this analysis was found 1.97 which is below the prescribed limit according to ICH guideline. It reveals that the system is suitable for further analysis.

\section{Calibration curve and Linearity:}

For the proposed method the calibration curves were constructed by plotting the absorbance the final concentration of the drug. The correspond ing regression equations were derived.

From the calibration plot it has been found that the linearity of said method is between $5-50 \mu \mathrm{g} / \mathrm{ml}$. Results of linearity study reveals that the method follows Beer's Lambert law. Further, limit of detection (LOD) and quantification (LOQ) of this method are $0.006 \mu \mathrm{g} / \mathrm{ml}$ and $0.018 \mu \mathrm{g} / \mathrm{ml}$ respectively.

\section{Precision}

The results of precision study show excellent repeatability and good precision of developed method. \% RSD value was not more than $2 \%$ in both intraday and interday precision study. For the interday precision, the range of RSD (\%) value was found between the ranges of 0.3 to 0.55 . For intraday precision the \% RSD values were found between the ranges of 0.1 to 0.4 for same analyst (Table 2) and when the experiment was carried out by another analyst, the range of RSD (\%) was between 0.3 to $0.8 \%$.

Table 1 : Selectivity

\begin{tabular}{|c|c|c|c|c|c|}
\hline Sr.No & $\begin{array}{l}\text { Conc. } \\
(\mu \mathrm{g} / \mathrm{ml})\end{array}$ & $\begin{array}{c}\mathrm{E}^{1 \% 1} \\
\mathrm{~cm}\end{array}$ & Mean & $\mathrm{SD}$ & $\begin{array}{c}\% \\
\text { RSD }\end{array}$ \\
\hline 1 & 20 & 155.5 & \multirow{10}{*}{156.75} & \multirow{10}{*}{2.89} & \multirow{10}{*}{1.97} \\
\hline 2 & 20 & 156.0 & & & \\
\hline 3 & 20 & 155.5 & & & \\
\hline 4 & 20 & 157.0 & & & \\
\hline 5 & 20 & 156.5 & & & \\
\hline 6 & 10 & 160.0 & & & \\
\hline 7 & 10 & 158.0 & & & \\
\hline 8 & 10 & 159.0 & & & \\
\hline 9 & 10 & 158.3 & & & \\
\hline 10 & 10 & 156.3 & & & \\
\hline
\end{tabular}


Table 1 : Precision Study

\begin{tabular}{|c|c|c|c|c|}
\hline \multicolumn{5}{|c|}{ Results of Intra-day precision } \\
\hline Sr.No & $\begin{array}{c}\text { Conce. } \\
(\mu \mathrm{g} / \mathrm{ml})\end{array}$ & Abs. & SD & $\%$ RSD \\
\hline 1 & 10 & 0.342 & 0.00229 & 0.401 \\
\hline 2 & 20 & 0.371 & 0.00143 & 0.382 \\
\hline 3 & 30 & 0.421 & 0.00231 & 0.523 \\
\hline
\end{tabular}

\section{Results of Interday precision- Same analyst}

\begin{tabular}{|c|c|c|c|c|}
\hline Sr.No & $\begin{array}{c}\text { Conce. } \\
(\mu \mathrm{g} / \mathrm{ml})\end{array}$ & Abs. & SD & \%RSD \\
\hline 1 & 10 & 0.332 & 0.00329 & 0.501 \\
\hline 2 & 20 & 0.383 & 0.00153 & 0.282 \\
\hline 3 & 30 & 0.434 & 0.00241 & 0.323 \\
\hline
\end{tabular}

Results of Interday precision- Different analyst

\begin{tabular}{|c|c|c|c|c|}
\hline Sr.No & $\begin{array}{c}\text { Conce. } \\
(\mu \mathrm{g} / \mathrm{ml})\end{array}$ & Abs. & SD & $\%$ RSD \\
\hline 1 & 10 & 0.340 & 0.00296 & 0.451 \\
\hline 2 & 20 & 0.385 & 0.00152 & 0.312 \\
\hline 3 & 30 & 0.429 & 0.00241 & 0.323 \\
\hline
\end{tabular}

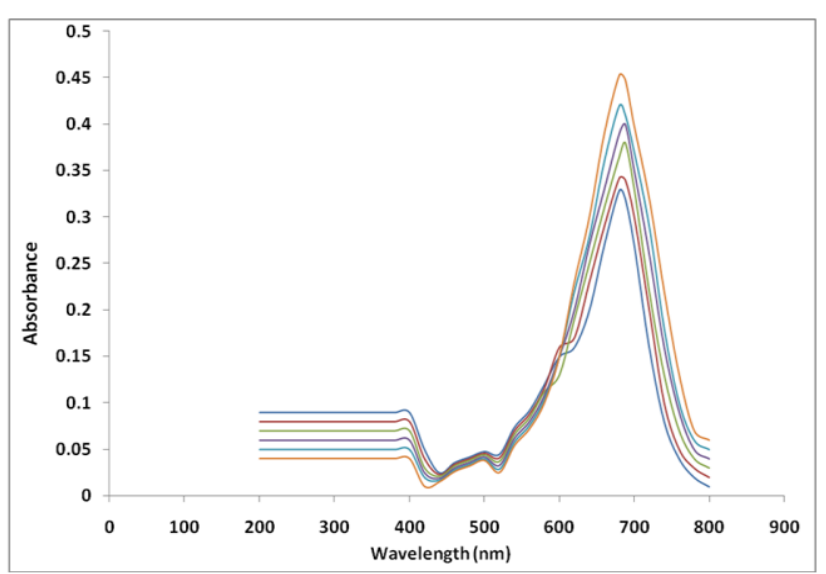

Figure 2: UV spectra of linearity

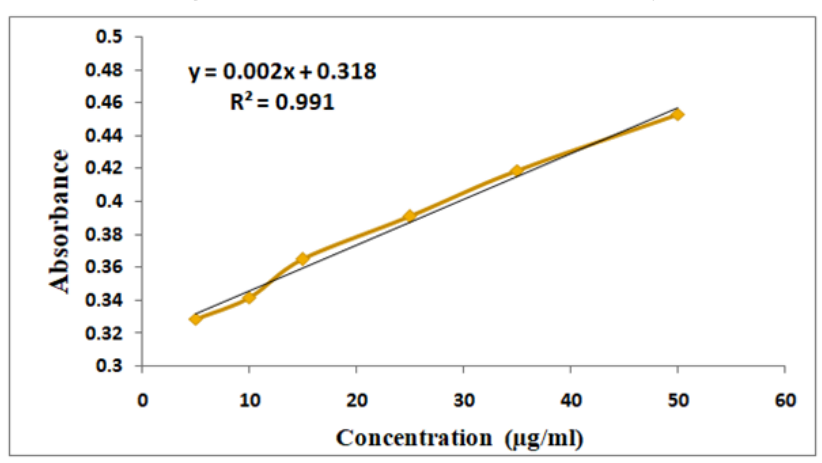

Figure 3: Calibration Curve

\section{Accuracy (Recovery)}

The absorbance values of solutions from each of the sets were recorded. Determination of accuracy of this method, different levels of drug concentrationslower concentration (LC), intermediate concentration (IC) and higher concentration (HC) were prepared from independent stock solutions and analysed. A comparison of these absorbance values with those obtained from the standard AP was made and after applying the appropriate dilution factor, the amounts of AP present we calculated.

Table 2 : Accuracy Study

\begin{tabular}{|l|l|l|l|l|}
\hline Sr. No & $\begin{array}{l}\text { Wt of } \\
\text { Sample } \\
\text { taken } \\
(\mathrm{mg})\end{array}$ & $\begin{array}{l}\text { Amount } \\
\text { of Std. } \\
\text { Added } \\
(\mathrm{mg})\end{array}$ & $\begin{array}{l}\text { Amount } \\
\text { found } \\
(\mathrm{mg})\end{array}$ & $\begin{array}{l}\% \\
\text { Recovery }\end{array}$ \\
\hline 1 & 200.04 & 50.03 & 251.2 & 100.45 \\
\hline 2 & 200.02 & 50.01 & 250.7 & 100.27 \\
\hline 3 & 200.01 & 100.02 & 300.08 & 100.02 \\
\hline 4 & 200.03 & 100.04 & 301.02 & 100.32 \\
\hline 5 & 200.04 & 150.05 & 350.18 & 100.03 \\
\hline 6 & 200.05 & 150.03 & 351.01 & 100.27 \\
\hline Mean & 100.23 & & & \\
\hline SD & 0.170 & & & \\
\hline \%RSD & 0.169 &
\end{tabular}

\section{Molar Absorptivity}

The molar absorptivity value of AP was calculated from the calibration curve using the formula, Molar absorptivity $=$ Slope $\mathrm{x}$ mol wt. $\mathrm{x} 10^{3}$ lit. $/ \mathrm{mol} / \mathrm{cm}=$ $919.01 \mathrm{lit} / \mathrm{mol} / \mathrm{cm}$

$$
=9.19 \times 10^{-3} \mathrm{lit} / \mathrm{mol} / \mathrm{cm}
$$

Sandell's sensitivity $=$ Molecular weight $/$ Molar absorptivity $=0.050 \mu \mathrm{g} / \mathrm{cm}$ 


\section{Assay of marketed formulation}

Here we take different Eliquis formulation for analysis in this study. The procedure to made sample solution as describe in experimental section. The absorbance values of these solutions were recorded at $680 \mathrm{~nm}$ and it was shown in Table 4. A comparison of these values with those obtained from the standard AP was made and after applying the appropriate dilution factor.

Table 3 : Assay of formulation

\begin{tabular}{|l|l|l|l|}
\hline Sr. No & $\begin{array}{l}\text { Amount } \\
\text { taken (mg) }\end{array}$ & $\begin{array}{l}\text { Amount } \\
\text { Found }\end{array}$ & $\begin{array}{l}\text { Percentage } \\
\text { assay (\%) }\end{array}$ \\
\hline 1 & 10 & 10.05 & 100.5 \\
\hline 2 & 10 & 10.04 & 100.4 \\
\hline 3 & 25 & 25.07 & 100.28 \\
\hline 4 & 25 & 24.98 & 99.92 \\
\hline 5 & 40 & 40.12 & 100.3 \\
\hline 6 & 40 & 40.07 & 100.2 \\
\hline Mean & 100.27 & & \\
\hline SD & 0.199 & & \\
\hline$\% R S D$ & 0.198 &
\end{tabular}

\section{CONCLUSION}

The present study reported successful development and evaluation of B.M reagent assisted detection method of Apixaban. The developed method selectively and sensitively deters mines Apixaban in bulk drug and its different formulations. Different validation study such as precision, accuracy, linearity study reveals that the developed method is fully validate as per ICH guidelines. The developed method does not need any expensive sophisticated equipment. The colored complex produce in this method is stable it shows high throughput property of this method. Hence, this method is commercially viable and valuable for its routine application in quality control laboratories for analysis of Apixaban.

\section{REFERENCES}

[1]. P. A. Wolf, R. D. Abbott, and W. B. Kannel, "Atrial fibrillation as an independent risk factor for stroke: the Framingham study," Stroke, vol. 22, no. 8, pp. 983-988, 1991.

[2]. L. Friberg, M. Rosenqvist, and G. Y. H. Lip, "Net clinical benefit of warfarin in patients with atrial fibrillation," Circulation, vol. 125, no. 19, pp. 2298-2307, 2012.

[3]. H. A. van den Ham, O. H. Klungel, D. E. Singer,H. G. M. Leufkens, and T. P. van Staa, "Comparative performance of ATRIA, CHADS2, and CHA2DS2-VASc risk scores predicting stroke in patients with atrial fibrillation," Journal of the American College of Cardiology, vol. 66, no. 17, pp. 1851-1859, 2015.

[4]. T. P. van Staa, E. Setakis, G. L. Di Tanna, D. A. Lane, and G. Y. H. Lip, "A comparison of risk stratification schemes for stroke in 79884 atrial fibrillation patients in general practice," Journal of 5rombosis and Haemostasis, vol. 9, no. 1, pp. 39-48, 2011.

[5]. S. J. Connolly, M. D. Ezekowitz, S. Yusuf et al., "Dabigatran versus warfarin in patients with atrial fibrillation," New England Journal of Medicine, vol. 361, no. 12, pp. 1139-1151, 2009.

[6]. R. P. Giugliano, C. T. Ruff, E. Braunwald et al., "Edoxaban versus warfarin in patients with atrial fibrillation," New England Journal of Medicine, vol. 369, no. 22, pp. 2093-2104, 2013.

[7]. C. B. Granger, J. H. Alexander, J. J. V. McMurray et al., "Apixaban versus warfarin in patients with atrial fibrillation," New England 
Journal of Medicine, vol. 365, no. 11, pp. 981992, 2011.

[8]. M. R. Patel, K. W. Mahaffey, J. Garg et al., "Rivaroxaban versus warfarin in nonvalvular atrial fibrillation," New England Journal of Medicine, vol. 365, no. 10, pp. 883-891, 2011.

[9]. Cheng JW, Barillari G. Non-vitamin K antagonist oral anticoagulants in cardiovascular disease management: evidence and unanswered questions. J Clin Pharm Ther. 2014;39:118-135.

[10]. Mani H, Lindhoff-Last E. New oral anticoagulants in patients with nonvalvular atrial fibrillation: a review of pharmacokinetics, safety, efficacy, quality of life, and cost effectiveness. Drug Des Devel Ther. 2014;8: 789-798.

[11]. Fenger-Eriksen C, Münster AM, Grove EL. New oral anticoagulants: clinical indications, monitoring and treatment of acute bleeding complications. Acta Anaesthesiol Scand. 2014;58:651-659.

[12]. Reilly PA, Lehr T, Haertter S, et al. The effect of dabigatran plasma concentrations and patient characteristics on the frequency of ischemic stroke and major bleeding in atrial fibrillation patients: the RE-LY Trial (Randomized Evaluation of Long-Term Anticoagulation Therapy). J Am Coll Cardiol. 2014;63:321-328.

[13]. Gong IY, Kim RB. Importance of pharmacokinetic profile and variability as determinants of dose and response to dabigatran, rivaroxaban, and apixaban. Can J Cardiol. 2013;29:S24-S33.

[14]. Scaglione F. New oral anticoagulants: comparative pharmacology with vitamin $\mathrm{K}$ antagonists. Clin Pharmacokinet. 2013;52(2):69-82. DOI: 10.1007/s40262- 0120030-9.

[15]. European Medicine Agency, Eliquis: Summary of Product Characteristics. Available at http://www.ema.europa.

$\mathrm{eu} /$

docs/en_GB/document_library/EPAR_

Product__ Information

human/002148/WC500107728. pdf. Accessed October 23rd, 2014.

[16]. Agnelli G, Buller HR, Cohen A, Curto M, Gallus AS, Johnson $\mathrm{M}$ et al. Oral apixaban for the treatment of acute venous thromboembolism. N Engl J Med. 2013 Aug29;369(9):799-808.

DOI:

10.1056/NEJMoa1302507

[17]. Cheng JW, Barillari G. Non-vitamin K antagonist oral anticoagulants in cardiovascular disease management:evidence and unanswered questions. J Clin Pharm Ther.2014;39(2):11835. DOI: $10.1111 /$ jcpt.12122

[18]. Bruins Slot KM, Berge E. Factor Xa inhibitors versus vitamin $\mathrm{K}$ antagonists for preventing cerebral or systemic embolism in patients with atrial fibrillation. Cochrane Database Syst Rev. 2013 Aug 8;8:CD008980. DOI: 10.1002/14651858.CD008980.pub2

[19]. Bauer KA. Pros and cons of new oral anticoagulants. Management of Thromboembolic Disease. Hematology Am Soc Hematol Educ Program. 2013;2013:464-70. DOI: 10.1182/asheducation-2013.1.464

[20]. 8. Levy JH, Faraoni D, Spring JL, Douketis JD, Samama CM. Managing New Oral Anticoagulants in the Perioperative and Intensive Care Unit Setting. Anesthesiology. 2013 Jun;118(6):1466-74. DOI: 10.1097/ ALN.0b013e318289bcba

[21]. Vílchez JA, Gallego P, Lip GYH. Safety of new oral anticoagulant drugs: a perspective. Ther Adv Drug Saf 2014;5(1):8-20. DOI: $10.1177 / 2042098613507945$

[22]. Pernod G, Albaladejo P, Godier A, Samama CM, Susen S, Gruel Y, et al. Management of major bleeding complicationsand emergency 
surgery in patients on longterm treatment with direct oral anticoagulants, thrombinor factorXa inhibitors: proposals of the workinggroup on perioperative haemostasis (GIHP) - March 2013. Arch Cardiovasc Dis. 2013;106(6-7):38293.DOI: 10.1016/j.acvd.2013.04.009

[23]. Dincq AS, Lessire S, Douxfils J, Dogné JM, Gourdin M, Mullier F. Management of NonVitamin K Antagonist Oral Anticoagulants in the Perioperative Setting. Biomed Res Int. 2014;2014:385014. DOI:10.1155/2014/385014

[24]. Eby C. Novel anticoagulants and laboratory testing. Int J Lab Hematol. 2013 Jun;35(3):2628. DOI: $10.1111 /$ ijlh.12065

[25]. Frost C, Nepal S, Wang J, Schuster A, Byon W, Boyd RA, et al. Safety, pharmacokinetics and pharmacodynamics of multiple oral doses of apixaban, a factor Xa inhibitor, in healthy subjects. Br J Clin Pharmacol. 2013 Nov;76(5):776-86. DOI: 10.1111/bcp.12106

[26]. Cui Y, Song Y, Wang J, Yu Z, Schuster A, Barrett YC, et al. Single- and multiple-dose pharmacokinetics, pharmacodynamics, and safety of apixaban in healthy Chinese subjects. Clin Pharmacol. 2013 Dec 6;5:177-84. DOI: 10.2147/CPAA.S51981

[27]. Delavenne X, Mismetti P, Basset T. Rapid determination of apixaban concentration in human plasma by liquid chromatography/tandem mass spectrometry:application to pharmacokinetic study. J Pharm Biomed Anal. 2013 May 5;7879:150-3. DOI: 10.1016/j.jpba.2013.02.007

\section{Cite this article as :}

Deepshikha Sharma, Vikramsinh R. Chauhan, Kartik B. Vyas, "Spectrophotometric Determination of Apixaban in Bulk Drug and Oral Dosage Formulation", International Journal of Scientific Research in Science and Technology (IJSRST), Online ISSN : 2395-602X, Print ISSN : 2395-6011, Volume 6 Issue 3, pp. 377-385, May-June 2019. Available at doi : https://doi.org/10.32628/IJSRST207263 Journal URL : http://ijsrst.com/IJSRST207263 